\title{
Hedgehog gene polymorphisms are associated with the risk of Hirschsprung's disease and anorectal malformation in a Chinese population
}

\author{
HONG GAO $^{1}$, DAJIA WANG ${ }^{1}$, YUZUO BAI ${ }^{1}$, JUAN ZHANG ${ }^{2}$, \\ MEI WU ${ }^{3}$, JIE MI $^{1}$, HUIMIN JIA ${ }^{1}$ and WEILIN WANG ${ }^{1}$ \\ ${ }^{1}$ Department of Pediatric Surgery, Shengjing Hospital of China Medical University, Shenyang, Liaoning 110004; \\ ${ }^{2}$ Department of Pediatric Surgery, Jinzhou Women and Children's Hospital, Jinzhou, Liaoning 121000; \\ ${ }^{3}$ Department of General Surgery, Children's Hospital of Hebei, Shijiazhuang, Hebei 050031, P.R. China
}

Received May 18, 2015; Accepted March 29, 2016

DOI: $10.3892 / \mathrm{mmr} .2016 .5139$

\begin{abstract}
Hedgehog (HH) is one of the key morphogens expressed in the gut mesenchyme that control animal development and tissue homeostasis. The HH gene has been shown to be closely associated with Hirschsprung's disease (HSCR) and anorectal malformations (ARMs); thus, it was hypothesized that $\mathrm{HH}$ signaling pathway-associated genes may be candidate genes for HSCR and ARMs. The present study aimed to evaluate whether polymorphisms in the $\mathrm{HH}$ gene were associated with HSCR and ARM in a Chinese population. HH gene variants (rs61730970, rs200798148 and rs146535482) were analyzed in whole blood samples from patients with HSCR and ARMs, as well as normal children (control group). The results suggested that, when the rs61730970, rs200798148 and rs146535482 alleles of the HH gene lacked particular single nucleotide polymorphisms (SNPs), the patients were associated with a greater risk of HSCR and/or ARM [HSCR: odds ratio $(\mathrm{OR})=1.543, \mathrm{P}=0.004 ; \mathrm{OR}=1.494, \mathrm{P}=0.007$; rs146535482: $\mathrm{OR}=1.556, \mathrm{P}=0.003$, respectively. $\mathrm{ARM}: \mathrm{OR}=1.528, \mathrm{P}=0.045$; $\mathrm{OR}=1.800, \mathrm{P}=0.007 ; \mathrm{OR}=1.743, \mathrm{P}=0.009$, respectively). Sequencing of rs61730970 and rs200798148 revealed a loss of heterozygosity and SNPs at these loci in patients with HSCR. Similarly, the sequencing of rs61730970 and rs146535482 revealed a loss of heterozygosity and SNPs at these loci in patients with ARM. Although preliminary, these results suggested that the HH gene may be involved in genetic interactions associated with the pathogenesis of HSCR and ARM.
\end{abstract}

Correspondence to: Professor Weilin Wang, Department of Pediatric Surgery, Shengjing Hospital of China Medical University, 36 Sanhao Street, Heping, Shenyang, Liaoning 110004, P.R. China E-mail: wangweilin54@sina.cn

Key words: Hirschsprung's disease, anorectal malformations, hedgehog gene, single nucleotide polymorphism

\section{Introduction}

Hirschsprung's disease (HSCR; also termed congenital aganglionic megacolon) represents the predominant genetic cause of functional intestinal obstruction, with an incidence of 1/5,000 live births, although there are differences in incidence among ethnic groups and there is a 4:1 male:female gender bias (1). HSCR is characterized by the abnormal development of the enteric nervous system (ENS), with aganglionosis in a distal segment of the bowel leading to intestinal dysfunction. HSCR typically occurs in infants and young children and the patients lose their normal bowel reflexes and fecal discharge barriers. Patients suffer from constipation, abdominal distension and vomiting, which affect growth and development. HSCR is a complex and heterogeneous disease; thus, there may be other unknown factors contributing to ENS development and HSCR pathogenesis (2). At present, the etiology of HSCR is thought to be multigenetic and multifactorial in origin (3). Although gaps in our understanding of HSCR remain, advances in genetic testing have led to an improved understanding of the disease (4).

Congenital anorectal malformations (ARMs) occur commonly in humans, with a reported incidence of 1:1,000-5,000 newborns $(5,6)$. The vast majority of children with ARMs are born with the anus in the wrong position. Furthermore, some patients have acute intestinal obstruction and difficultly in defecating after birth. A minority of children with ARMs show no or only mild symptoms $(5,6)$. ARMs is thought to occur in the developing embryo as a result of genetic factors; however, the underlying pathogenesis of ARMs has yet to be fully elucidated. Numerous technical advances have been made in the surgical treatment of ARMs; however, patients with intermediate-type and high-type ARMs often continue to have postoperative anal dysfunctions.

Numerous signaling molecules have been shown to be involved in the development of HSCR in the embryo, including RET, endothelin receptor type B, endothelin 3, endothelin-converting enzyme 1, SRY (sex determining region Y)-box 10 (SOX10), glial cell-derived neurotrophic factor, 
neurturin, paired-like homeobox 2b (PHOX2B), transcription factor 4 (TCF4) and zinc finger E-box binding homeobox 2 (ZEB2 or ZFHX1B) (7-11). Those suggested to be involved in ARM include sonic hedgehog ( $\mathrm{SHH})$, bone morphogenetic protein 4, HOX, fibroblast growth factor 10, Wnt, Notch and Hedgehog (HH) (12-18). Embryonic development is regulated by a number of complex signaling pathways. A previous study indicated that the $\mathrm{HH}$ signaling pathway exerts a key role in the initiation, patterning and morphogenesis of the anus (13); and a subsequent study reported the involvement of the $\mathrm{HH}$ signaling pathway in the axial patterning of the gastrointestinal tract (19).

The role of inductive interactions in animal development has long been recognized; however, only recently have the signaling molecules mediating these interactions been identified (20). Prominent among these are the Hedgehog (Hh) family of proteins, which are a group of closely associated secreted proteins encoded by a gene family originally identified through mutations of $\mathrm{HH}$, a segment polarity gene in Drosophila (20). The $\mathrm{HH}$ proteins are evolutionarily conserved signaling molecules that control the normal growth and patterning of diverse animals, including Drosophila and humans (20). As with other signaling molecules, $\mathrm{HH}$ is expressed in the notochord, neural tube, brain, polarizing activities of the limbs of the development zone and the intestine (20). Genetic analyses have revealed that the majority of segment polarity genes are involved in the transduction of the $\mathrm{HH}$ signal or the signal encoded by the gene wingless (WNT), a member of the WNT family of signaling proteins (21). Therefore, the investigation of segment polarity genes has permitted the delineation of these two signaling pathways, and efforts are under way to characterize in molecular detail the precise biochemical mechanisms underlying HH signal transduction (21). Similar to other signals regulating embryonic development, members of the Hh family, including SHH, Indian hedgehog homolog (IHH) and Desert hedgehog homolog (DHH), are involved in a wide variety of processes, ranging from the control of left-right asymmetry of the body to the specification of individual types of cell within the neural tube and brain (21). In addition, as with other embryonic signals, the aberrant activity of the $\mathrm{HH}$ signaling pathway has been linked to abnormalities associated with specific diseases.

A previous study suggested that certain single nucleotide polymorphisms (SNPs) in the HH gene may be responsible for an underlying genetic predisposition to particular diseases (22). Therefore, the present study examined a larger cohort and extended the evaluation of the genetic association between SNPs of the HH gene with HSCR and ARM. Screening of the HH gene, in particular within the rs61730970, rs200798148 and rs146535482 loci, was performed to identify genetic polymorphisms associated with HSCR and ARM.

\section{Materials and methods}

Patients and controls. The present study was approved by the Ethics Committee of the China Medical University (Shenyang, China; ethical no. 2013PS07K). Blood samples (5 ml) from 200 HSCR (139 male and 61 female) and 100 ARM (67 male and 33 female) patients were collected at the Departments of
Pediatric Surgery of the Shengjing Hospital of China Medical University and the Jinzhou Women and Children's Hospital (Liaoning, China) between January 2008 and December 2013. For the purposes of the study, patients with familial constipation or other congenital gastrointestinal malformations were excluded. Patients in the case groups of HSCR and ARM were aged between 0.5 and 3.5 years (average age, $1.5 \pm 0.3$ years). The control group was matched to the HSCR and ARM groups with respect to the ratio of boys:girls and age (age range, 0.5 to 2 years).

Extraction of DNA. Blood samples $(5 \mathrm{ml})$ were collected from the HSCR, ARM and control group patients, and $200 \mu \mathrm{l}$ venous blood samples were treated with $15 \mathrm{~g} / \mathrm{l}$ EDTA (Beijing bioco Laibo Technology, Co., Ltd., Beijing, China) as an anticoagulant. Genomic DNA was extracted using the Blood Genome DNA Extraction kit (cat. no. 9450; Takara Biotechnology Co., Ltd., Dalian, China), according to the manufacturer's protocol. The absorbance values at 260 and $280 \mathrm{~nm}\left(A_{260} / A_{280}\right)$ were measured by spectrophotometry (NanoVue ${ }^{\mathrm{TM}}$ Plus Spectrophotometer; GE Healthcare Life Sciences, Chalfont, UK), and an absorbance between 1.6 and 2 was considered to meet the experimental requirements. The integrity and purity of DNA were determined by $1.5 \%$ agarose gel electrophoresis. DNA templates were stored in a freezer at $-70^{\circ} \mathrm{C}$ until further use.

Polymerase chain reaction (PCR) and DNA sequence analysis. The rs61730970, rs200798148 and rs146535482 loci from the $\mathrm{HH}$ gene were selected for the SNP analysis, based on their minor allele frequencies. Specific primers for the $\mathrm{HH}$ gene were designed using the DNASTAR primer design program, and synthesized by Liuhe Huada Gene Technology, Co., Ltd. (Beijing, China). The primer sequences used for PCR were as follows: rs61730970-1, 5'-GGGTTA GCAAGCACTTCA-3' and rs61730970-2, 5'-AAGCCAACC TTTATTCCACT-3' (product size, 341 bp); rs200798148-1, 5'-ТСССТТАТСТССТТСАТСТ-3' and rs200798148-2, 5'-AAGCCAACCTTTATTCCAC-3' (product size, 265 bp); rs146535482-1, 5'-CACCTCAGCCTCACAAAGT-3' and rs146535482-2, 5'-TTCCATCTGGTCCAAGTAG-3' (product size, $303 \mathrm{bp}$ ). The primers exhibited no homology with other genes, as determined from a Basic Local Alignment Search Tool (http://blast.ncbi.nlm.nih.gov/Blast.cgi) analysis. For PCR, a $50 \mu 1$ reaction system included 10X PCR buffer solution, $1 \mathrm{mmol} / 1 \mathrm{MgCl}_{2}, 0.1 \mathrm{mmol} / 1$ deoxynucleotides, $10 \mathrm{pmol} / 1$ each of the upstream and downstream primers, 100 ng DNA template and 1 U Taq DNA polymerase (Takara Biotechnology Co., Ltd.). The PCR conditions were as follows: $95^{\circ} \mathrm{C}$ predegeneration for $3 \mathrm{~min}$, then $95^{\circ} \mathrm{C}$ denaturation for $30 \mathrm{sec}$, followed by annealing at $53-58^{\circ} \mathrm{C}$ for $30 \mathrm{sec}$ and elongation at $72^{\circ} \mathrm{C}$ for $1 \mathrm{~min}$ in 30 cycles, and finally, the reaction was terminated by incubation at $72^{\circ} \mathrm{C}$ for $7 \mathrm{~min}$. The PCR products were electrophoresed on a $1.5 \%$ agarose gel containing the DL 2000 DNA Marker, stained with ethidium bromide (both Beijing bioco Laibo Technology, Co., Ltd.), and visualized using an automatic gel documentation system (AzureSpot Analysis Software System; Azure Biosytems, Dublin, CA, USA). Subsequently, the PCR products were purified using 75\% isopropanol (Beijing Qixiang Hongye 
Table I. Allele and genotype frequency distribution in patients with Hirschsprung's disease, and controls.

\begin{tabular}{|c|c|c|c|c|c|c|}
\hline Polymorphism & Type & HSCR & Controls & $X^{2}$ & P-value & OR $(95 \% \mathrm{CI})$ \\
\hline \multirow[t]{5}{*}{ rs61730970 } & $\mathrm{AA}$ & 107 & 76 & & & 1.00 (ref.) \\
\hline & AG & 74 & 98 & 8.465 & 0.004 & $0.536(0.352-0.817)$ \\
\hline & GG & 19 & 26 & 0.009 & 0.923 & $1.033(0.532-2.007)$ \\
\hline & A & 288 & 250 & & & \\
\hline & G & 112 & 150 & 8.195 & 0.004 & $1.543(1.146-2.078$ \\
\hline \multirow[t]{5}{*}{ rs200798148 } & $\mathrm{CC}$ & 102 & 73 & & & 1.00 (ref.) \\
\hline & $\mathrm{CT}$ & 77 & 99 & 7.419 & 0.006 & $0.557(0.365-0.850)$ \\
\hline & TT & 21 & 28 & 0.012 & 0.911 & $1.037(0.547-1.966)$ \\
\hline & $\mathrm{C}$ & 281 & 245 & & & \\
\hline & $\mathrm{T}$ & 119 & 155 & 7.194 & 0.007 & $1.494(1.113-2.004)$ \\
\hline \multirow[t]{5}{*}{ rs146535482 } & $\mathrm{CC}$ & 101 & 72 & & & 1.00 (ref.) \\
\hline & CG & 78 & 96 & 6.381 & 0.012 & $0.579(0.379-0.886)$ \\
\hline & GG & 21 & 32 & 0.448 & 0.504 & $1.238(0.662-2.316)$ \\
\hline & $\mathrm{C}$ & 280 & 240 & & & \\
\hline & $\mathrm{G}$ & 120 & 160 & 8.791 & 0.003 & $1.556(1.161-2.085)$ \\
\hline
\end{tabular}

OR, odds ratio; CI, confidence interval.

Trading, Co., Ltd., Beijiing, China) and sequenced using an automatic sequencer (BGISEQ-1000; BGI Shenzhen, Shenzhen, China).

Statistical analysis. Statistical analyses were conducted using SPSS software, version 13.0 (SPSS, Inc., Chicago, IL, USA). $\chi^{2}$ tests were performed to determine whether each polymorphism was in Hardy-Weinberg equilibrium within the normal control and patient groups. The unconditional logistic regression model was used to analyze the association between the risk of each SNP and HSCR and ARM. Multiplicative interactions have previously been considered to be suitable for the detection of possible gene-environment interactions $(23,24)$. The $\chi^{2}$ test was also used to determine the significance of the association of the allele frequencies between the normal control group and the patient groups. $\mathrm{P}<0.05$ was considered to indicate a statistically significant difference.

\section{Results}

PCR amplification of HH gene. PCR amplification of the $\mathrm{HH}$ gene was successfully performed. The amplified segments of rs61730970 (601 bp), rs200798148 (401 bp) and rs146535482 (503 bp) were of lengths 341, 265 and 303 bp, respectively, which were in accordance with the theoretical lengths. The amplification products were highly expressed, without any apparent non-specific bands (Fig. 1).

Distribution of rs61730970, rs200798148 and rs146535482 allele and genotype frequencies in the HSCR, ARM and control groups. Genotype distributions in the three SNPs were in accordance with the Hardy-Weinberg equilibrium ( $\mathrm{P}>0.05$; Fig. 2). rs61730970, rs200798148 and rs146535482 of the $\mathrm{HH}$ gene genotype were revealed to be particularly associated with a greater risk of HSCR and ARM (Tables I and II).
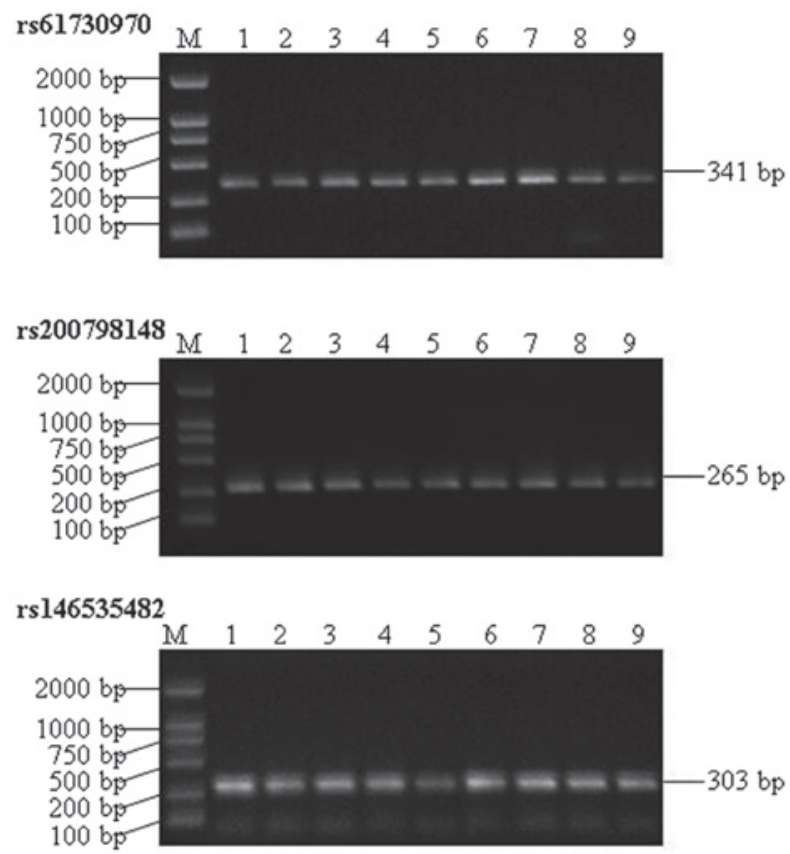

Figure 1. Agarose gel electrophoresis of the PCR products of rs61730970, rs200798148 and rs146535482. M, DL2000 marker; lanes 1-3 were PCR amplification products of the HSCR group; lanes 4-6 were PCR amplification products of the ARM group; lanes 7-9 were PCR amplification products of the control group. PCR, polymerase chain reaction.

Regarding the genotype level in rs61730970, HSCR was negatively correlated with GG homozygosity, and positively correlated with AG heterozygosity and AA homozygosity $(\mathrm{P}=0.008)$, which revealed that the risk of HSCR was significantly increased among patients with the AG or AA genotype. In the SNP of rs61730970 of the HSCR group, the allele frequencies revealed a trend for a significant association 
Table II. Allele and genotype frequency distribution in patients with anorectal malformations, and controls.

\begin{tabular}{|c|c|c|c|c|c|c|}
\hline Polymorphism & Type & ARM & Controls & $X^{2}$ & P-value & OR $(95 \% \mathrm{CI})$ \\
\hline \multirow[t]{5}{*}{ rs61730970 } & AA & 53 & 36 & & & 1.00 (ref.) \\
\hline & AG & 35 & 52 & 5.872 & 0.115 & $0.475(0.260-0.871)$ \\
\hline & GG & 12 & 14 & 0.202 & 0.653 & $0.817(0.337-1.976)$ \\
\hline & A & 141 & 122 & & & \\
\hline & G & 59 & 78 & 4.008 & 0.045 & $1.528(1.008-2.316)$ \\
\hline \multirow[t]{5}{*}{ rs200798148 } & $\mathrm{CC}$ & 59 & 37 & & & 1.00 (ref.) \\
\hline & $\mathrm{CT}$ & 32 & 51 & 9.343 & 0.002 & $0.393(0.215-0.720)$ \\
\hline & $\mathrm{TT}$ & 9 & 12 & 0.130 & 0.718 & $0.837(0.317-2.209)$ \\
\hline & $\mathrm{C}$ & 150 & 125 & & & \\
\hline & $\mathrm{T}$ & 50 & 75 & 7.273 & 0.007 & $1.800(1.172-2.765)$ \\
\hline \multirow[t]{5}{*}{ rs146535482 } & $\mathrm{CC}$ & 55 & 36 & & & 1.00 (ref.) \\
\hline & $\mathrm{CG}$ & 33 & 46 & 5.902 & 0.015 & $0.470(0.254-0.867)$ \\
\hline & GG & 12 & 18 & 0.028 & 0.867 & $1.076(0.475-2.534)$ \\
\hline & $\mathrm{C}$ & 143 & 118 & & & \\
\hline & G & 57 & 82 & 6.891 & 0.009 & $1.743(1.149-2.645)$ \\
\hline
\end{tabular}

OR, odds ratio; CI, confidence interval.

A

rs61730970
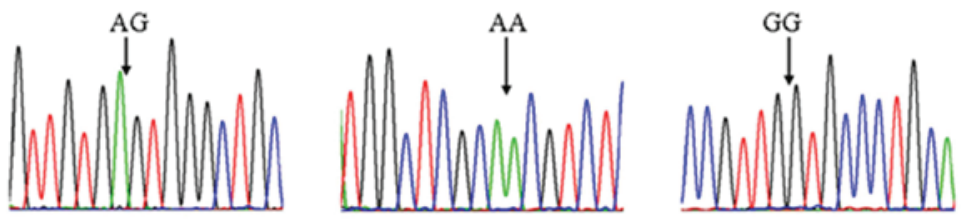

B
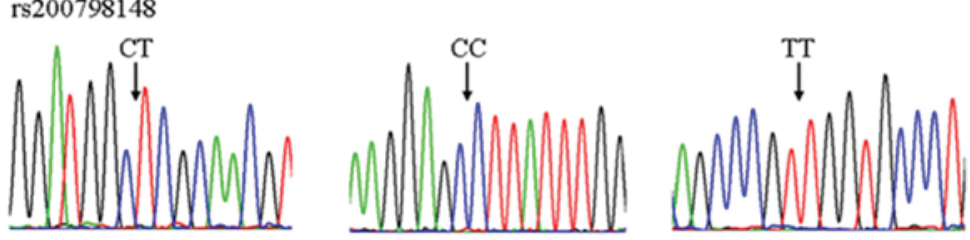

C
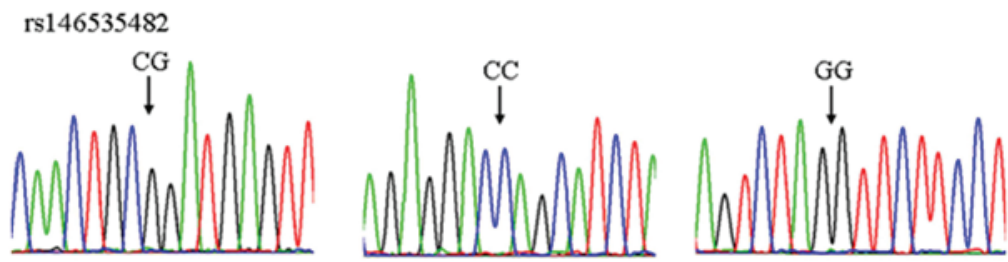

Figure 2. The sequencing results of different genotypes of rs61730970, rs200798148 and rs146535482. (A) AG, AA and GG sequencing results of rs61730970. (B) CT, CC, and TT sequencing results of rs200798148. (C) CG, CC, and GG sequencing results of rs146535482. The arrow denotes the location of the single nucleotide polymorphism.

with the $\mathrm{G}$ allele $(\mathrm{P}=0.004)$. Regarding the genotype level in rs200798148, HSCR was negatively correlated with TT homozygosity and positively correlated with CT heterozygosity and $\mathrm{CC}$ homozygosity $(\mathrm{P}=0.014)$, which revealed that the risk of HSCR was significantly increased among patients with the CT or CC genotype. In the SNP of rs 200798148 of the HSCR group, the allele frequencies revealed a trend for a significant association with the $\mathrm{T}$ allele $(\mathrm{P}=0.007)$. Regarding the genotype level in rs146535482, HSCR was negatively correlated with GG homozygosity, and positively correlated with CG heterozygosity and $\mathrm{CC}$ homozygosity $(\mathrm{P}=0.011)$, revealing that the risk of HSCR was significantly increased among patients with the CG or CC genotype. In the SNP of rs146535482 of the HSCR group, the allele frequencies revealed a trend for a significant association with the $\mathrm{G}$ allele $(\mathrm{P}=0.003)$. The differences in the genotypes and allele distributions were statistically significant among various clinical types in the HSCR variants rs61730970, rs200798148 and rs146535482 (Table III). 
Table III. Allele and genotype frequency distribution in HSCR.

\begin{tabular}{|c|c|c|c|c|c|c|c|}
\hline \multirow{3}{*}{$\begin{array}{l}\text { Polymorphism } \\
\text { rs61730970 }\end{array}$} & \multirow{3}{*}{$\begin{array}{c}\text { Group } \\
\text { HSCR }\end{array}$} & \multirow{3}{*}{$\begin{array}{c}\text { Case }(n) \\
200\end{array}$} & \multicolumn{3}{|c|}{ Genotype frequency $(\%)$} & \multicolumn{2}{|c|}{ Allele frequency } \\
\hline & & & AA & $\mathrm{AG}$ & GG & A & G \\
\hline & & & $107(53.50)$ & $74(37.00)$ & $19(9.50)$ & $288(72.00)$ & $112(28.00)$ \\
\hline & Controls & 200 & $98(49.00)$ & $76(38.00)$ & $26(13.00)$ & $250(62.50)$ & $150(37.50)$ \\
\hline & & & \multicolumn{2}{|c|}{$X^{2}=9.689$} & $\mathrm{P}=0.008$ & $X^{2}=8.195$ & $\mathrm{P}=0.004$ \\
\hline \multirow{4}{*}{ rs200798148 } & & & $\mathrm{CC}$ & $\mathrm{CT}$ & $\mathrm{TT}$ & $\mathrm{C}$ & $\mathrm{T}$ \\
\hline & HSCR & 200 & $102(51.00)$ & $77(38.50)$ & $21(10.50)$ & $281(70.25)$ & $119(29.75$ \\
\hline & Controls & 200 & $73(36.50)$ & $99(49.50)$ & $28(14.00)$ & $245(61.25)$ & $155(38.75)$ \\
\hline & & & \multicolumn{2}{|c|}{$X^{2}=8.556$} & $\mathrm{P}=0.014$ & $X^{2}=7.194$ & $\mathrm{P}=0.007$ \\
\hline \multirow{4}{*}{ rs 146535482} & & & $\mathrm{CC}$ & CG & GG & $\mathrm{C}$ & G \\
\hline & HSCR & 200 & $101(50.50)$ & $78(39.00)$ & $21(10.50)$ & $280(70.00)$ & $120(30.00$ \\
\hline & & 200 & $72(36.00)$ & $96(48.00)$ & $32(16.00)$ & $240(60.00)$ & $160(40.00)$ \\
\hline & & & \multicolumn{2}{|c|}{$X^{2}=9.006$} & $\mathrm{P}=0.011$ & $X^{2}=8.791$ & $\mathrm{P}=0.003$ \\
\hline
\end{tabular}

HSCR, Hirschsprung's disease.

Table IV. Allele and genotype frequency distribution in ARM.

\begin{tabular}{|c|c|c|c|c|c|c|c|}
\hline Polymorphism & Group & Case (n) & \multicolumn{3}{|c|}{ Genotype frequency $(\%)$} & \multicolumn{2}{|c|}{ Allele frequency } \\
\hline & & & AA & $\mathrm{AG}$ & GG & A & G \\
\hline \multirow[t]{4}{*}{ rs61730970 } & ARM & 100 & $53(26.50)$ & $35(17.50)$ & $12(6.00)$ & $141(70.50)$ & $59(29.50)$ \\
\hline & Controls & 100 & $36(18.00)$ & $50(25.00)$ & $14(7.00)$ & $122(61.00)$ & $78(39.00)$ \\
\hline & & & \multicolumn{3}{|c|}{$X^{2}=6.048$} & $X^{2}=4.008$ & $\mathrm{P}=0.045$ \\
\hline & & & $\mathrm{CC}$ & $\mathrm{CT}$ & TT & $\mathrm{C}$ & $\mathrm{T}$ \\
\hline \multirow[t]{4}{*}{ rs200798148 } & ARM & 100 & $59(29.50)$ & $32(16.00)$ & $9(4.50)$ & $150(75.00)$ & $50(25.00)$ \\
\hline & Controls & 100 & $37(18.50)$ & $51(25.50$ & $12(6.00)$ & $125(62.50)$ & $75(37.50)$ \\
\hline & & & \multicolumn{3}{|c|}{$X^{2}=9.820 \quad \mathrm{P}=$} & $X^{2}=7.273$ & $\mathrm{P}=0.007$ \\
\hline & & & $\mathrm{CC}$ & $\mathrm{CG}$ & GG & $\mathrm{C}$ & G \\
\hline \multirow[t]{3}{*}{ rs146535482 } & ARM & 100 & $55(27.50)$ & $33(16.50)$ & $12(6.00$ & $143(71.50)$ & $57(28.50)$ \\
\hline & Controls & 100 & $36(18.00)$ & $46(23.00)$ & $18(9.00)$ & $118(59.00)$ & $82(41.00)$ \\
\hline & & & \multicolumn{2}{|c|}{$X^{2}=7.306$} & & $X^{2}=6.891$ & $\mathrm{P}=0.009$ \\
\hline
\end{tabular}

ARM, anorectal malformation.

For the genotype level in rs61730970, ARM was negatively correlated with GG homozygosity and positively correlated with AG heterozygosity and AA homozygosity $(\mathrm{P}=0.049)$, revealing that the risk of ARM was significantly increased among patients with the AG or AA genotype. In the SNP of rs61730970 of the ARM group, the allele frequencies revealed a trend for a significant association with the $G$ allele $(\mathrm{P}=0.045)$. For the genotype level in rs200798148, ARM was negatively correlated with TT homozygosity and positively correlated with $\mathrm{CT}$ heterozygosity and CC homozygosity $(\mathrm{P}=0.007)$, which revealed that the risk of ARM was significantly increased among patients with the CT or CC genotype. In the SNP of rs200798148 of the ARM group, the allele frequencies revealed a trend for a significant association with the $\mathrm{T}$ allele $(\mathrm{P}=0.007)$. For the genotype level in rs146535482, ARM was negatively correlated with GG homozygosity and positively correlated with CG heterozygosity and CC homo- zygosity $(\mathrm{P}=0.026)$, which revealed that the risk of ARM was significantly increased among patients with the CG or CC genotype. In the SNP of rs146535482 of the ARM group, the allele frequencies revealed a trend for a significant association with the $\mathrm{G}$ allele $(\mathrm{P}=0.009)$. The differences in the genotypes and allele distributions were statistically significant among the various clinical types in the ARM variants rs61730970, rs200798148 and rs146535482 (Table IV).

Sequence variants of rs61730970, rs200798148 and rs146535482 in the HSCR and ARM groups. In the HSCR group, a loss of heterozygosity and SNPs were detected in the rs61730970 and rs200798148 sequences by sequencing. For rs61730970, a substitution was detected at the $166^{\text {th }}$ codon of GCA $\rightarrow$ GTA (alanine $\rightarrow$ valine) in 17 patients; for rs200798148, a loss of heterozygosity was detected in 21 patients, and the sequence lost one ' $\mathrm{A}$ ' at its $125^{\text {th }}$ codon 
A

rs61730970
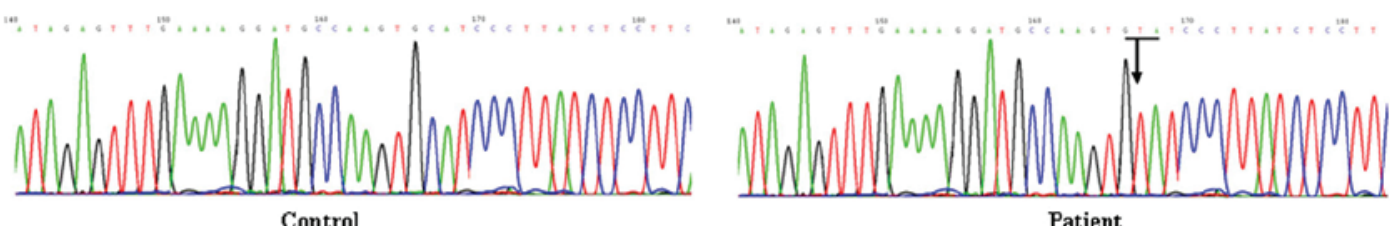

Patient

B

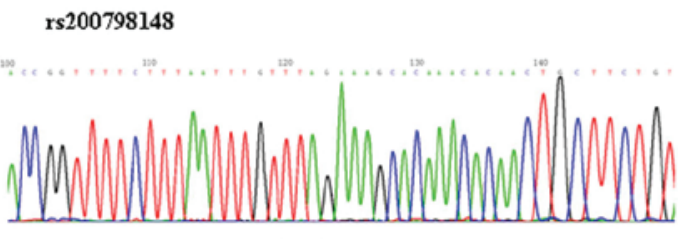

Control

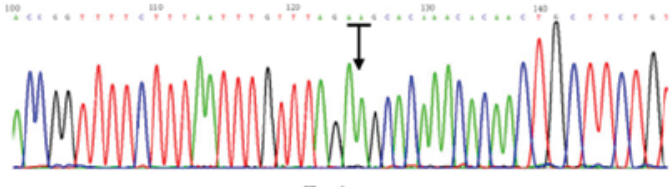

Patient

Figure 3. A novel mutation of rs61730970 and rs200798148 in HSCR. (A) The sequencing results of rs61730970 in the patients' and the controls' groups: The mutation was found at the codon, 166th GCA $\rightarrow$ GTA (alanine $\rightarrow$ valine). (B) The sequencing results of rs200798148 in the patients' and the controls' groups: An 'A' was lost at its 125 th codon. The arrows denote the codon point.

A
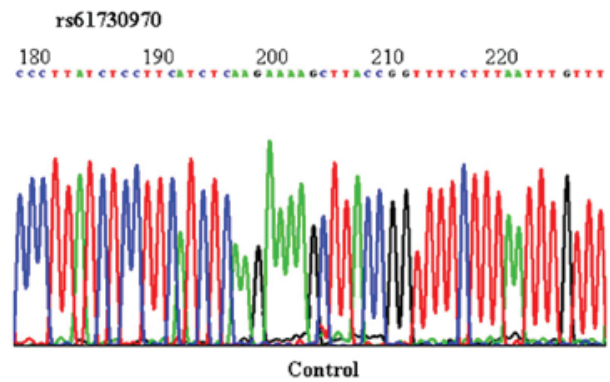

B

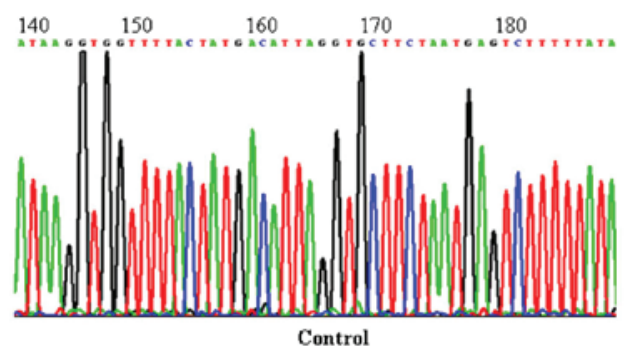

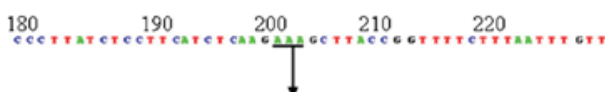
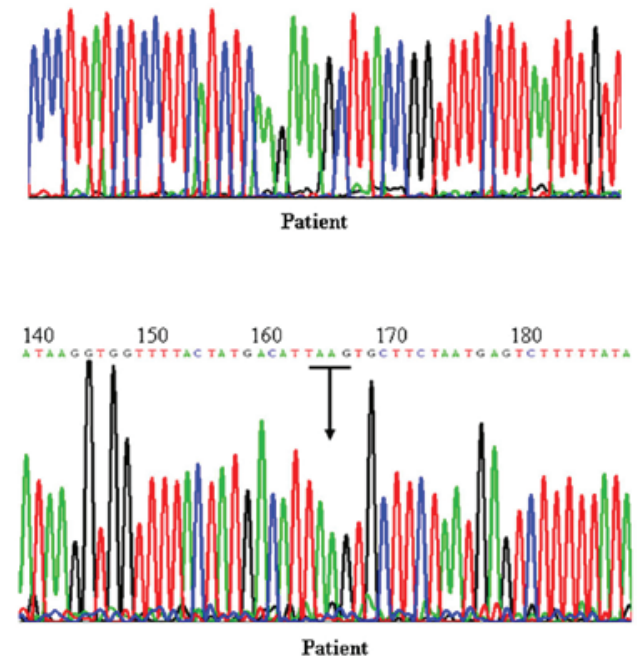

Figure 4. A novel mutation of rs61730970 and rs146535482 in ARM. (A) The sequencing results of rs61730970 in the patients' and the controls' groups: An 'A' was lost at its 203rd codon. (B) The sequencing results of rs146535482 in the patients' and the controls' groups: The mutation was found at the 166th codon, $\mathrm{AGG} \rightarrow$ AAG (arginine $\rightarrow$ lysine). The arrows denote the codon point.

(Fig. 3). Sequencing of rs146535482 did not identify any abnormalities associated with HSCR.

In the ARM group, a loss of heterozygosity and SNPs were detected in the rs61730970 and rs146535482 sequences. For rs61730970, a loss of heterozygosity was detected in 19 patients and one 'A' was lost at the at the $203^{\text {rd }}$ codon; for rs146535482, a substitution was detected at the $166^{\text {th }}$ codon of AGG $\rightarrow$ AAG (arginine $\rightarrow$ lysine) in 33 patients (Fig. 4). Sequencing of rs200798148 did not identify any abnormalities associated with ARM.

\section{Discussion}

HSCR is a common congenital malformation of the gastrointestinal tract. It is thought to be due to stagnation of the digestive tract into nerve cells during embryonic development. In addition, it has been suggested that environmental and genetic factors may have an important role in the occurrence of $\operatorname{HSCR}(1,3)$.

The vast majority of ARM children do not have an anus in the normal anal position, some patients have acute intestinal obstruction after birth and some have difficultly in defecating. A small minority of ARM children show no or only mild symptoms $(5,6)$. Despite its clinical relevance, the development of ARM remains poorly understood in the context of development of the hindgut (25). The genetics of ARM are extremely complex and numerous genes have previously been associated with the pathogenesis, including BMPs, HOX, SHH, and so forth $(14,15,20)$. However, at present, no common consensus exists regarding the pathogenesis of ARM. 
HSCR and ARM are complex diseases, and at least 17 genes have been associated with the pathogenesis of HSCR and ARM. HH family proteins are secreted signaling molecules that control animal development and the balancing of tissues $(26,27)$. They are produced as precursors that are activated by autocatalytic processing to generate sterol modification, in particular palmitoylation, activity in the $\mathrm{N}$-terminal signaling domain (28-30). Lipid modifications influence $\mathrm{HH}$ signaling, although its precise function has yet to be fully elucidated (31). The HH pathway can be activated by any one of the three homologs of the Drosophila proteins, namely $\mathrm{SHH}$, $\mathrm{DHH}$ or IHH, of which $\mathrm{SHH}$ is the best characterized signaling protein involved in early patterning and cell-fate specification in various systems (32). In all mammals investigated, $\mathrm{SHH}$, $\mathrm{IHH}$ and $\mathrm{DHH}$ are expressed in the developing gut tube. $\mathrm{SHH}$ and $\mathrm{IHH}$ are expressed in the epithelium, whereas DHH is specifically expressed in Schwann cells, peripheral nerves and endothelial cells (21). In the mouse, during gut organogenesis, $\mathrm{SHH}$ and $\mathrm{IHH}$ are co-expressed in gut primitive endoderm epithelium at the early somite stage (8.5 days post-coitum), prior to the enteric neural crest cells reaching the stomach, which usually occurs at embryonic day 10.5 (E10.5). At the latter stages, from early stomach development (E10) to the initiation of epithelial cytodifferentiation at E15.5, SHH and IHH are persistently, although differentially, expressed in the developing guts (21).

The precursor protein of $\mathrm{HH}$ protein has a molecular weight of $\sim 45 \mathrm{kDa}$. The C-terminal portion of the $\mathrm{HH}$ precursor has zymogen activity; $\mathrm{HH}$ is cleaved into a $\mathrm{C}$-terminal peptide with a molecular weight of $\sim 25 \mathrm{kDa}$ of no known function, and an N-terminal fragment ( $\mathrm{HH}-\mathrm{N})$, which constitutes the biologically active portion of $\mathrm{HH}$ (33). During autoprocessing, a cholesterol group is attached to the C-terminus of $\mathrm{HH}-\mathrm{N}$, which is expressed in the form designated as HH-Np (34). It is considered that cholesterol helps to maintain the HH-Np cell membrane, and also limits the scope of HH activity. However, in mice that were modified to express a form of Shh lacking the cholesterol modification ( $\mathrm{N}-\mathrm{SHH}$ ), short-range $\mathrm{HH}$ signaling was maintained, while long-range signaling was defective, resulting in the loss of digits and proper patterning in the developing limb, thereby suggesting differential requirements for the cholesterol $\mathrm{HH}$ signaling pathway (35). HH proteins are further modified by palmitoylation at a highly conserved $\mathrm{N}$-terminal cysteine residue (36). Thus far, the function of the $\mathrm{HH}$ protein in the signaling pathway is relatively unexplored in other mammals.

The aim of the present study was to determine the role of the ENS on the development of the HH cascade in HSCR and ARM. Particular loci in the HH gene (rs61730970, rs200798148 and rs146535482) exhibited SNPs and loss of heterozygosity in a number of patients with HSCR and ARM, and these variations occurred much less frequently in the normal control patients. Heterozygous change was observed for rs61730970 in 17 patients, whereas a loss of rs200798148 correlated with the loss of heterozygosity in 21 patients of the HSCR group. By contrast, with rs61730970, a loss of heterozygosity was observed in 19 patients, while the heterozygous change with rs146535482 was observed with 33 patients in the ARM group. Furthermore, the presence of a heterozygous form of the rs61730970 codon (alanine at position $166 \rightarrow$ valine) in the HSCR group, and a heterozygous form of the rs146535482 codon (arginine at position $166 \rightarrow$ lysine) in the ARM group, may represent the key mutation.

The present study also aimed to examine the risk and potential association of $\mathrm{HH}$ gene polymorphisms in Chinese patients with HSCR and ARM. The association between specific genotypes and HSCR and ARM was assessed using logistic regression analysis, or an examination of the $95 \%$ confidence interval. The risk of HSCR and ARM increased as presumptive high-risk genotypes increased for the combined genotypes of the $\mathrm{HH}$ heterozygosity genotype. Essentially, the results suggested that polymorphisms in the $\mathrm{HH}$ gene, in particular at the rs61730970, rs200798148 and rs146535482 loci, were associated with susceptibility to HSCR and ARM. In terms of the genotype and allele distribution of rs61730970, rs200798148, and rs146535482, various changes were shown to be statistically significant, which may affect the clinical performance. In addition, the sequence analysis performed in the present study revealed that the $\mathrm{HH}$ gene may influence the risk of common developmental abnormalities.

In conclusion, the present study demonstrated an association between genetic polymorphisms at the $\mathrm{HH}$ gene and HSCR and ARM. An increased risk of HSCR and ARM was most evident for patients who possessed the heterozygosity-associated alleles, indicating that the effect was present in the Chinese population examined in the present study. These results suggested that heterozygosity variations in the $\mathrm{HH}$ gene have an important role in the development of HSCR and ARM, and the present study may provide novel insights into the pathogenesis of HSCR and ARM.

\section{Acknowledgements}

This study was supported by grants from the National Natural Science Foundation of China (grant nos. 81270436 and 81170334) and the Shenyang Science and Technology Plan Project (grant no. F13-316-1-01).

\section{References}

1. Amiel J, Sproat-Emison E, Garcia-Barcelo M, Lantieri F, Burzynski G, Borrego S, Pelet A, Arnold S, Miao X, Griseri P, et al: Hirschsprung disease, associated syndromes and genetics: A review. J Med Genet 45: 1-14, 2008.

2. Saeed A, Barreto L, Neogii SG, Loos A, McFarlane I and Aslam A: Identification of novel genes in Hirschsprung disease pathway using whole genome expression study. J Pediatr Surg 47: 303-307, 2012.

3. Passarge E and Bruder E: Genetic bases of Hirschsprung's disease. Pathologe 28: 113-118, 2007 (In German).

4. El-Nachef W and Grikscheit T: Enteric nervous system cell replacement therapy for Hirschsprung disease: Beyond tissue-engineered intestine. Eur J Pediatr Surg 24: 214-218, 2014.

5. Rintala RJ: Congenital anorectal malformations: Anything new? J Pediatr Gastroenterol Nutr 48 (Suppl 2): S79-S82, 2009.

6. Bán G, Németh $P$ and Túri S: Neurovesical dysfunction in children with anorectal malformations. Orv Hetil 147: 1645-1649, 2006 (In Hungarian).

7. Sánchez-Mejías A, Fernández RM, López-Alonso M, Antiñolo G and Borrego S: New roles of EDNRB and EDN3 in the pathogenesis of Hirschsprung disease. Genet Med 12: 39-43, 2010.

8. Pan ZW, Lou J, Luo C, Yu L and Li JC: Association analysis of the SOX10 polymorphism with Hirschsprung disease in the Han Chinese population. J Pediatr Surg 46: 1930-1934, 2011.

9. Fernandez RM, Ruiz-Ferrer M, Lopez-Alonso M, Antiñolo G and Borrego S: Polymorphisms in the genes encoding the 4 RET ligands, GDNF, NTN, ARTN, PSPN, and susceptibility to Hirschsprung disease. J Pediatr Surg 43: 2042-2047, 2008. 
10. Kwon MJ, Lee GH, Lee MK, Kim JY, Yoo HS, Ki CS, Chang YS, Kim JW and Park WS: PHOX2B mutations in patients with Ondine-Hirschsprung disease and a review of the literature. Eur J Pediatr 170: 1267-1271, 2011.

11. Gregory-Evans CY, Vieira H, Dalton R, Adams GG, Salt A and Gregory-Evans K: Ocular coloboma and high myopia with Hirschsprung disease associated with a novel ZFHX1B missense mutation and trisomy 21. Am J Med Genet A 131: 86-90, 2004.

12. Seifert AW, Harfe BD and Cohn MJ: Cell lineage analysis demonstrates an endodermal origin of the distal urethra and perineum. Dev Biol 318: 143-152, 2008.

13. van den Brink GR: Hedgehog signaling in development and homeostasis of the gastrointestinal tract. Physiol Rev 87: 1343-1375, 2007.

14. Torihashi S, Hattori T, Hasegawa H, Kurahashi M, Ogaeri T and Fujimoto T: The expression and crucial roles of BMP signaling in development of smooth muscle progenitor cells in the mouse embryonic gut. Differentiation 77: 277-289, 2009.

15. Zacchetti G, Duboule D and Zakany J: Hox gene function in vertebrate gut morphogenesis: The case of the cecum. Development 134: 3967-3973, 2007.

16. Fairbanks TJ, De Langhe S, Sala FG, Warburton D, Anderson KD, Bellusci S and Burns RC: Fibroblast growth factor 10 (Fgf10) invalidation results in anorectal malformation in mice. J Pediatr Surg 39: 360-365; discussion 360-365, 2004

17. Tai CC, Sala FG, Ford HR, Wang KS, Li C, Minoo P, Grikscheit TC and Bellusci S: Wnt5a knock-out mouse as a new model of anorectal malformation. J Surg Res 156: 278-282, 2009.

18. Ngan ES, Garcia-Barceló MM, Yip BH, Poon HC, Lau ST, Kwok CK, Sat E, Sham MH, Wong KK, Wainwright BJ, et al: Hedgehog/Notch-induced premature gliogenesis represents a new disease mechanism for Hirschsprung disease in mice and humans. J Clin Invest 121: 3467-3478, 2011.

19. Lees C, Howie S, Sartor RB and Satsangi J: The hedgehog signalling pathway in the gastrointestinal tract: Implications for development, homeostasis, and disease. Gastroenterology 129: $1696-1710,2005$

20. Odent S, Atti-Bitach T, Blayau M, Mathieu M, Aug J, Delezo de AL, Gall JY, Le Marec B, Munnich A, David V and Vekemans M: Expression of the Sonic hedgehog (SHH) gene during early human development and phenotypic expression of new mutations causing holoprosencephaly. Hum Mol Genet 8: 1683-1689, 1999.

21. Chan LH, Wang W, Yeung W, Deng Y, Yuan P and Mak KK Hedgehog signaling induces osteosarcoma development through Yap1 and H19 overexpression. Oncogene 33: 4857-4866, 2014

22. Casey JP, Magalhaes T, Conroy JM, Regan R, Shah N, Anney R, Shields DC, Abrahams BS, Almeida J, Bacchelli E, et al: A novel approach of homozygous haplotype sharing identifies candidate genes in autism spectrum disorder. Hum Genet 131: 565-579, 2012.
23. Lu J, Yang L, Zhao H, Liu B, Li Y, Wu H, Li Q, Zeng B, Wang Y, Ji W and Zhou Y: The polymorphism and haplotypes of PIN1 gene are associated with the risk of lung cancer in Southern and Eastern Chinese populations. Hum Mutat 32: 1299-1308, 2011.

24. Yang L, Li Y, Cheng M, Huang D, Zheng J, Liu B, Ling X, Li Q, Zhang X, Ji W, et al: A functional polymorphismatmicroRNA-629-binding site in the 3'-untranslated region of NBS1 gene confers an increased risk of lung cancer in Southern and Eastern Chinese population. Carcinogenesis 33: 338-347, 2012.

25. Moore SW: Associations of anorectal malformations and related syndromes. Pediatr Surg Int 29: 665-676, 2013.

26. Ingham PW, Nakano Y and Seger C: Mechanisms and functions of Hedgehog signalling across the metazoa. Nat Rev Genet 12: 393-406, 2011

27. McMahon AP, Ingham PW and Tabin CJ: Developmental roles and clinical significance of hedgehog signaling. Curr Top Dev Biol 53: 1-114, 2003

28. Porter JA, Ekker SC, Park WJ, von Kessler DP, Young KE, Chen CH, Ma Y, Woods AS, Cotter RJ, Koonin EV and Beachy PA: Hedgehog patterning activity: Role of a lipophilic modification mediated by the carboxy-terminal autoprocessing domain. Cell 86: 21-34, 1996.

29. Porter JA, Young KE and Beachy PA: Cholesterol modification of hedgehog signaling proteins in animal development. Science 274: 255-259, 1996.

30. Pepinsky RB,Zeng C, Wen D, Rayhorn P, Baker DP, Williams KP, Bixler SA, Ambrose CM, Garber EA, Miatkowski K, et al: Identification of a palmitic acid-modified form of human Sonic hedgehog. J Biol Chem 273: 14037-14045, 1998.

31. Mann RK and Beachy PA: Novel lipid modifications of secreted protein signals. Annu Rev Biochem 73: 891-923, 2004.

32. Pettigrew CA, Asp E and Emerson CP Jr: A new role for Hedgehogs in juxtacrine signaling. Mech Dev 131: 137-149, 2014.

33. Jiang SQ and Paulus H: A high-throughput, homogeneous, fluorescence polarization assay for inhibitors of hedgehog protein autoprocessing. J Biomol Screen 15: 1082-1087, 2010.

34. Tokhunts R, Singh S, Chu T, D'Angelo G, Baubet V, Goetz JA, Huang Z, Yuan Z, Ascano M, Zavros Y, et al: The full-length unprocessed hedgehog protein is an active signaling molecule. J Biol Chem 285: 2562-2568, 2010.

35. Palm W, Swierczynska MM, Kumari V, Ehrhart-Bornstein M, Bornstein SR and Eaton S: Secretion and signaling activities of lipoprotein-associated hedgehog and non-sterol-modified hedgehog in flies and mammals. PLoS Biol 11: e1001505, 2013.

36. Lee JD, Kraus P, Gaiano N, Nery S, Kohtz J, Fishell G, Loomis CA and Treisman JE: An acylatable residue of Hedgehog is differentially required in Drosophila and mouse limb development. Dev Biol 233: 122-136, 2001. 